\title{
Introduction of Wireless Services and Devices in a Hospital Environment Following a Risk-based EMC Approach
}

\author{
Mumpy Das \\ University of Twente \\ Enschede, The Netherlands \\ mumpy.das@utwente.nl
}

\author{
Silvo Jeunink \\ University of Twente \\ Enschede, The Netherlands
}

\author{
Robert Vogt-Ardatjew \\ University of Twente \\ Enschede, The Netherlands
}

\author{
Bärbel van den Berg \\ Medisch Spectrum Twente Hospital \\ Enschede, The Netherlands
}

\author{
Frank Leferink \\ University of Twente, Enschede \\ Thales Nederland, Hengelo \\ The Netherlands
}

\begin{abstract}
This paper emphasizes the need for a risk-based EMC approach in the hospital environment. A modern hospital with various kinds of wireless medical electronic equipment especially in the intensive care, operation theatre, neonatology, etc., pollutes the environment by creating electromagnetic interference with other equipment in the vicinity or even implanted equipment inside the patient. Even following the IEC 60601-1-2 product standard for medical equipment which is based on a rule-based approach, suppressing electromagnetic interference effectively is an arduous task. In the upcoming years, the number of wireless devices in a modern hospital will significantly increase and might cause EMC instability in this highly complex system. Hence, an urgent requirement for an advanced and smarter approach leads to the use of a risk-based EMC approach. The detrimental effect of intentional sources causing electromagnetic interference in the hospital environment is briefly discussed. The risk-based EMC approach has been applied in the Medisch Spectrum Twente hospital, where it was discovered that wireless devices such as digital mobile radio, cell phone, and radio frequency identification equipment critically affect equipment pumps and patient monitors.
\end{abstract}

Keywords- electromagnetic compatibility, hospital, rule-based EMC, risk-based EMC

\section{INTRODUCTION}

Digitalization of medical devices in the early 1970s has created various benefits such as better unit control, enhanced portability, sustainable monitoring, low power usage, interoperability, and multiple functionalities which lead to better treatment of the patients [1]. However, the risk of electromagnetic interference (EMI) due to the increase of modern electronic equipment in the hospital environment was acknowledged in the mid-1990s, and EMI issues are continuously being reported [2]. According to the MAUDE's database report [2], as shown in Fig. 1, the number of adverse events due to EMI has grown exponentially from 2010 to 2018

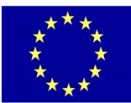

The research leading to these results has received funding from the European Union's Horizon 2020 research and innovation programme under the Marie Skłodowska-Curie Grant Agreement No 812.790 (MSCA-ETN PETER). This publication reflects only the authors' view, exempting the European Union from any liability. Project website: $\underline{\text { http://etn-peter.eu/ }}$

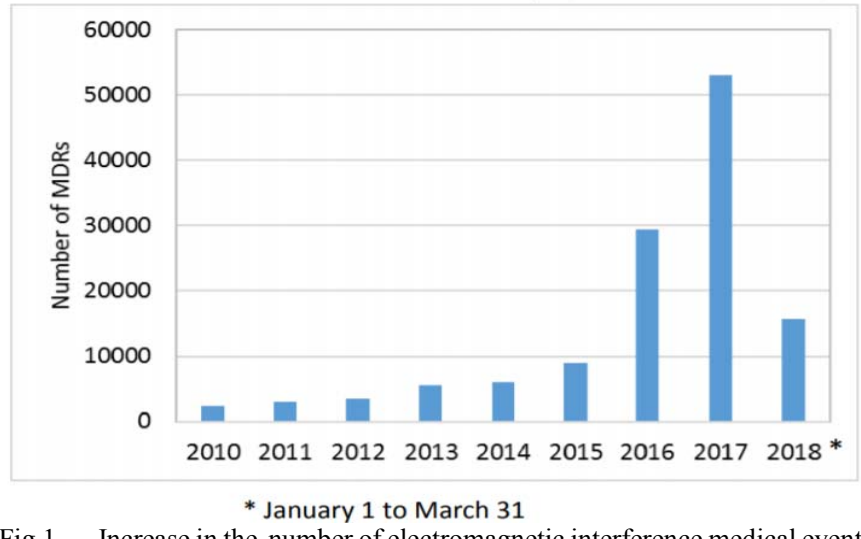

Fig.1. Increase in the number of electromagnetic interference medical events in the USA [2]

in the USA. Data from other countries are not available. This trend is expected to continue especially due to the implementation of new technologies, such as 5G [3], if no extra precautions are enforced.

As stated by [4] and [5], some of the main reasons behind such exponential growth are the low intrinsic electromagnetic compatibility (EMC) of old electronic medical equipment (ME) with newer technologies in the complex electromagnetic (EM) environments, increase in the demand of electronic ME with low power consumption, which leads to weaker internal signal, making the equipment more vulnerable to EMI, compact structure of $\mathrm{ME}$, and usage of various kind wireless data communication, faster-switching power devices, etc. These factors create a complex EM environment with possible EMI issues of diverse nature. Nowadays, electronic ME is becoming increasingly ubiquitous in hospitals especially in the intensive care (IC), operation theatre (OT), and neonatology department. The presence of ME and the risk of EMI in such crucial areas of hospital enhances the risk of adverse medical events as vital as the death of a patient. Hence, the smart and feasible approach is required to abate EMI in the hospital environment where human safety is at stake. The presence of multiple and various EMI sources, intentional and unintentional, in hospital, makes it difficult to completely eradicate EMI following a simple 
ruleset. However, it can be controlled by using various measures at a certain level. In order to achieve a high level of EMC in a hospital environment, various methods have been proposed among which rule-based approach, based on various standards [6] and guidelines [7], and gained considerable popularity in the industrial environment, where it was implemented initially. The rule-based approach is the conventional approach where it is assumed that every equipment fulfills the requirements in standards, and where the standards are fitted for the operational use environment. In most cases, the equipment is checked for immunity and emissions as a standalone object in laboratory conditions, although it is intended to be used in a densely populated and complex environment. Moreover, the high care spaces such as IC or OT can work as semi-reverberant environments for electromagnetic fields rather than a free space (FS) environment [8]. Presence of different types of reflectors, coated glass mirrors, or other equipment, creates more coupling paths for the reflected waves that further increase the complexity of the environment. Although the coupling between individual $\mathrm{ME}$ can be isolated, the oversight of the whole system is a challenge due to the many variables such as spatial and temporal behavior, the effect of the environment, or the severity or probability of malfunction. Therefore, a more consistent and beneficial, risk-based EMC approach is required that incorporates the whole matrix of sources and victims, along with the corresponding variables [9]. This approach is in use for some decades in defense and other industries where professional equipment is being developed. The risk-based approach has recently been introduced in the latest guide for the EMC Directive [6] and in the fourth edition of IEC 60601-1-2 [5], which is the EMC standard for medical equipment. The risk-based approach for naval ships has been described in [10], among others. Lloyd's Register has implemented this also in the Lloyd's Rules [10]. The same strategy of risk-based approach has now been proposed for the Medisch Spectrum Twente (MST) hospital in the Netherlands.

To address the issue of introducing wireless services and devices in a hospital, we initially defined the EM environment by discussing the wireless devices which are the sources of EM radiation as well as list the possible victims that could be present inside the hospital environment. By introducing the severity and probability of EMI parameters to those items, we used the source-victim matrix tool [11] to understand their interactions and find out the exact ME with the highest EMI risk. Then, we provided a suggestion to deal with the sensitive cases by performing an experimental analysis and thus ensure the minimization of EMI risk in those groups. Furthermore, we tackled the effect of a fact that the hospital environment can behave as a semi-reverberant environment and not as FS.

\section{SOURCES OF EMI IN A HOSPITAL ENVIRONMENT}

Sources of EMI can be both intentional and unintentional [12]. The unintentional emitters are for example magnetic resonance imaging (MRI) scanner, which uses the EM field to generate anatomical images, which, as reported in [13], creates interference in implantable medical equipment such as stents, clips, prostheses, pacemakers and neurostimulators. The same study shows that a large plasma screen display in the waiting room and other places of the hospital may create interference and disturb the ultrasound ME. All of this equipment complies with the applicable rule-based standards. On the other hand, the intentional sources transmit EM energy purposely and effectively, often with comparatively higher power. Although those emissions are controlled and intended, they might become a challenge because the number of such wireless devices is expanding rapidly worldwide [14]. Mobile phones, laptops, tablets, walkie-talkie (W-T), gaming consoles, etc. were banned a decade ago, but are now allowed in the hospital. Some hospitals follow strict rules about using mobile or other wireless devices by having specific places dedicated for the usage of mobile equipment and achieving EMC by maintaining certain distances from the critical ME. In most hospitals however, visitors, health care providers, as well as patients are all using various wireless devices on a daily basis. Extensive usage of these intentional emitters in a hospital leads to polluting the environment dynamically and often unpredictably.

The intentional emitters which are commonly found in Dutch hospitals include C2000 TETRA radio, cell phone (CP), Wi-Fi, Bluetooth, long range ultrahigh frequency (UHF) radiofrequency identification (RFID) like UPASS and TRANSIT, etc. This rapid usage of emitters in the hospital environment has some major consequences. For instance, in [13], it is reported that the C2000 TETRA radio used by the police near a hospital created interference with vital hospital equipment like breath-test and radar speed machines. It is also stated there that the Health Canada's Medical Devices Bureau received 36 reports related to the EMI out of which four were caused by wireless cellular phones, one case of premature failure of pacemaker due to interference from electronic article surveillance (EAS) system, and two cases of failure of implantable cardiac pacemakers. Furthermore, an experiment was conducted to check the susceptibility of ECG due to iPod $\mathrm{Nano}^{\mathrm{TM}}$, portable $2.4 \mathrm{GHz}$ phone, portable $5.8 \mathrm{GHz}$ phone, Gameboy $^{\mathrm{TM}}$, etc. showing heartbeat changes ranging from 14 to 28 beats per minute due to EMI [15]. It is clear that the expansion of wireless technology used in the hospital for monitoring, control, tracking, record-keeping, etc., potentially increases the risk of EMI [16].

Acceptance of RFID for the betterment of healthcare also affects the EM environment [13]. In general, there are two types of RFID, one has active tags and transmits information, the other has passive tags which can be read by a transceiver placed nearby. The research conducted at Vrije University in Amsterdam showed that out of 41 medical devices including ventilators, syringe pumps, pacemaker, and dialysis machines, 24 were disturbed by passive RFID [17].

\section{INTRODUCTION OF WIRELESS SERVICES AND DEVICES}

This section discusses the aspects of introducing wireless services and devices in a hospital environment. Traditionally, following the rule-based EMC approach, all other equipment present in the environment fulfills radiated immunity 
requirements assuming that these immunity requirements cover all frequency bands and all field strengths where that equipment can be exposed to. It is, already now, obvious that rule-based is not possible, as, for instance:

- a lot of older ME has been designed when some of the current wireless technology did not exist;

- a lot older ME has been designed in a time it was assumed that no wireless services would be used in a hospital, as these were prohibited in those places;

- a lot of ME has been tested only at $3 \mathrm{~V} / \mathrm{m}$, while wireless emitters can create higher field strengths nearby, and especially in complex multipath environments.

So, when introducing wireless devices in a hospital environment the risk of EMI has to be analyzed. The risk analysis is based upon the first-order assumption that the electric field strength lowers with distance. If we assume that manufacturers of a device follows the 61000-4-3 Ed.3 2006 standard [18] which states the immunity level of $3 \mathrm{~V} / \mathrm{m}$, then a minimum separation distance can be found via the basic equation (assuming far field conditions and a low-gain monopole antenna) by

$$
d=\frac{K}{E} \sqrt{P}
$$

where $P$ is the effective radiated power (ERP) in $\mathrm{W}, d$ is the separation distance in $\mathrm{m}$, and $E$ is the field strength in $\mathrm{V} / \mathrm{m}$. The constant $K$ has a value of 7 for equipment, and 3 for mobile radio transmitters if the ERP value of the emitter is not known [18]. The values of ERP, as well as frequency bands of typical wireless emitters present in a hospital environment, can be found in Table I.

TABLE I. Wireless TransmitTERS PRESENT IN Hospitals WITH PROBABILITY

\begin{tabular}{|c|c|c|c|c|c|c|}
\hline \multirow{2}{*}{$\begin{array}{c}\text { Device } \\
\text { C2000 } \\
\text { Hand- } \\
\text { held } \\
\end{array}$} & \multirow{2}{*}{$\begin{array}{c}\text { Technique } \\
\text { TETRA }\end{array}$} & \multicolumn{2}{|c|}{$\begin{array}{c}\text { (uplink) band } \\
\text { (MHz) }\end{array}$} & \multirow{2}{*}{$\begin{array}{r}\text { ERP } \\
\text { (W) } \\
1.80\end{array}$} & \multirow{2}{*}{$\begin{array}{c}\text { Source } \\
\text { numbe } \\
\text { r }\end{array}$} & \multirow{2}{*}{$\begin{array}{c}\begin{array}{c}\text { Probabil } \\
\text {-ity }\end{array} \\
-\end{array}$} \\
\hline & & 380 & 390 & & & \\
\hline \multirow[t]{2}{*}{ W-T } & DMR & 442 & 448 & 1.00 & \multirow[t]{2}{*}{1} & \multirow[t]{2}{*}{ Probable } \\
\hline & PMR446 & 450 & 470 & 1.00 & & \\
\hline \multirow[t]{8}{*}{$\mathrm{CP}$} & \multirow[t]{2}{*}{ GSM } & 880 & 915 & 2.00 & 2 & \multirow[t]{2}{*}{ Probable } \\
\hline & & 1700 & 1785 & 1.00 & 3 & \\
\hline & \multirow[t]{2}{*}{ UMTS } & 880 & 915 & 0.25 & 4 & \multirow{2}{*}{ Moderate } \\
\hline & & 1920 & 1980 & 0.25 & 5 & \\
\hline & \multirow[t]{4}{*}{ LTE } & 832 & 862 & 0.20 & 6 & \multirow[t]{4}{*}{ Moderate } \\
\hline & & 880 & 915 & 0.20 & 7 & \\
\hline & & 1700 & 1785 & 0.20 & 8 & \\
\hline & & 2500 & 2615 & 0.20 & 9 & \\
\hline \multirow{4}{*}{$\begin{array}{c}\text { CP, } \\
\text { Compu } \\
\text { ter, etc }\end{array}$} & \multirow[t]{3}{*}{ Wi-fi } & 2400 & 2483.5 & 0.06 & 10 & \multirow[t]{3}{*}{ Minor } \\
\hline & & 5150 & 5350 & 0.12 & 11 & \\
\hline & & 5470 & 5725 & 0.12 & 12 & \\
\hline & Bluetooth & 2400 & 2483.5 & 0.06 & 13 & Minor \\
\hline \multirow[t]{3}{*}{$\begin{array}{l}\text { Nedap } \\
\text { RFID }\end{array}$} & $\begin{array}{l}\text { UPASS } \\
\text { (EPC gen } \\
\text { II) }\end{array}$ & 865 & 868 & 2.00 & 14 & Probable \\
\hline & \multirow[t]{2}{*}{ TRANSIT } & 433 & 434 & 0.00 & 15 & \multirow[t]{2}{*}{ Minor } \\
\hline & & 2446 & 2453 & 0.31 & 16 & \\
\hline
\end{tabular}

Table II shows how $E$ calculated using equation (1), where $K$ is equal to 7 , changes with distance from the ME. It is shown that the FS values reach up to $10 \mathrm{~V} / \mathrm{m}$ even at $100 \mathrm{~cm}$ and quickly decay with distance. However, according to [18], the statistical fluctuations of the field strength like reflections from floor, ceiling, walls etc., can increase this value by $6 \mathrm{~dB}$. Furthermore, in an extreme case of an environment as reflective as a reverberation chamber, $E$ can increase even by $20 \mathrm{~dB}$ [19]. In this extreme case, the resonating scattered components become stronger than the directly coupled component, which actually makes spatial separation less effective, and it will not follow the exponential decay, as shown in [8]. Due to the very strong statistical variations, the latter effect is not included in Table II and is subject to future studies.

TABLE II. E CALCULATED FOR DIFFERENT $d$ FROM VARIOUS WIRELESS TRANSMITTERS

\begin{tabular}{|c|c|c|c|c|c|c|c|}
\hline \multirow[t]{2}{*}{ Device } & \multirow[t]{2}{*}{ Technique } & \multicolumn{3}{|c|}{$E[\mathrm{~V} / \mathrm{m}]$ at $100 \mathrm{~cm}$} & \multicolumn{3}{|c|}{$E[\mathrm{~V} / \mathrm{m}]$ at $300 \mathrm{~cm}$} \\
\hline & & FS & $6 \mathrm{~dB}$ & $\begin{array}{l}20 \\
\text { dB }\end{array}$ & FS & $6 \mathrm{~dB}$ & $\begin{array}{l}20 \\
\text { dB }\end{array}$ \\
\hline $\begin{array}{l}\text { C2000 } \\
\text { hand- } \\
\text { held }\end{array}$ & TETRA & 9.4 & 18.8 & 94 & 3.1 & 6.3 & 31 \\
\hline \multirow[t]{2}{*}{ W-T } & PMR446 & 5 & 9.9 & 50 & 1.7 & 3.3 & 17 \\
\hline & DMR & 7 & 14 & 70 & 2.3 & 5.4 & 23 \\
\hline \multirow[t]{4}{*}{$\mathrm{CP}$} & \multirow[t]{2}{*}{ GSM } & 9.9 & 19.8 & 99 & 3.3 & 6.6 & 33 \\
\hline & & 7 & 14 & 70 & 2.3 & 5.4 & 23 \\
\hline & UMTS & 3.5 & 7 & 35 & 1.2 & 2.3 & 12 \\
\hline & LTE & 3.1 & 6.3 & 31 & 1 & 2.1 & 10 \\
\hline \multirow{3}{*}{$\begin{array}{l}\text { CP, } \\
\text { comput } \\
\text { er, etc. }\end{array}$} & \multirow[t]{2}{*}{ Wi-fi } & 1.7 & 3.4 & 17 & 0.6 & 1.1 & 6 \\
\hline & & 2.4 & 4.8 & 24 & 0.8 & 1.6 & 8 \\
\hline & Bluetooth & 1.7 & 3.4 & 17 & 0.6 & 1.1 & 11 \\
\hline \multirow[t]{3}{*}{$\begin{array}{l}\text { Nedap } \\
\text { RFID }\end{array}$} & $\begin{array}{c}\text { UPASS } \\
\text { (EPC gen } \\
\text { II) }\end{array}$ & $\begin{array}{l}9.9 \\
\end{array}$ & 19.8 & 99 & 3.3 & 6.6 & 66 \\
\hline & \multirow[t]{2}{*}{ TRANSIT } & 0.1 & 0.2 & 1 & 0 & 0 & 0 \\
\hline & & 3.9 & 7.8 & 39 & 1.3 & 2.6 & 13 \\
\hline
\end{tabular}

A risk assessment method needs to be considered to know about the severity of the risk of inducing EMI in/from the introduced systems. This risk assessment method can be done using the steps described below and has been applied in a case study in the MST hospital in Enschede, the Netherlands.

Step 1: Determine the scope of the EM environment:

Firstly, the EM environment has to be described to establish the base for interactions and possible exceptions used in the next steps. Here the department of neonatology is taken under consideration. Neonatology is suitable for this approach as it contains various critical and life-supporting ME meant for vulnerable patients, and behave as similar indoor environments. Fig. 2 shows the EM environment of a neonatology room. The medical equipment present inside the room is only considered as a potential victim of EMI.

Step 2: List all ME (victims) in the EM environment:

The possible victims, or the ME present in the environment, are marked in Fig. 2. They are all compliant with IEC 60601-1-2 EMC standard. The immunity levels of all the present devices 


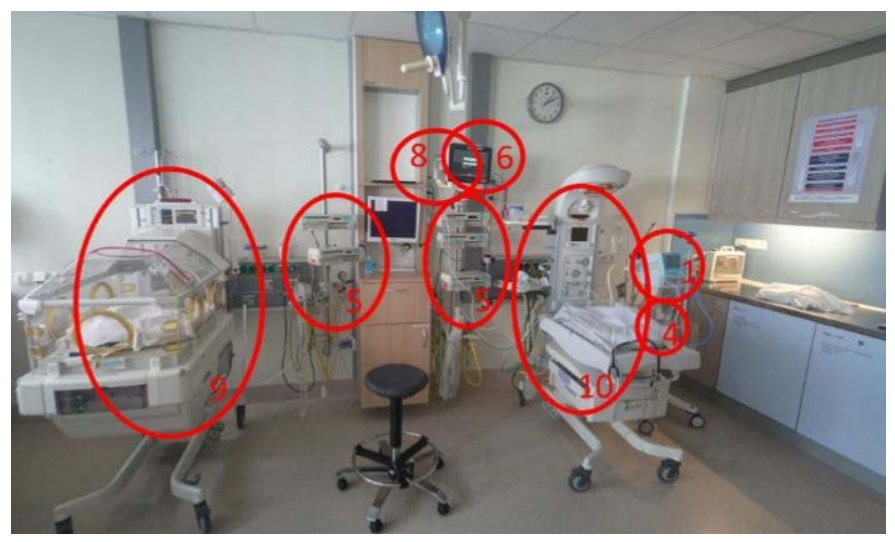

Fig. 2. The neonatology environment with marked potential victim ME

in the room are from the EMC manual [18] and are listed in Table III. The severity parameter was estimated with the help of various aspects like the effect of a short malfunctioning of the ME on patients as well as its detectability. The severity can be critical, serious, or negligible.

TABLE III. The List of The Victims In NeONATOLOgy with SeVErity

\begin{tabular}{|c|c|c|c|c|}
\hline No & Name & Function & EMC & Severity \\
\hline 1 & $\begin{array}{l}\text { Acutronic } \\
\text { Fabian }\end{array}$ & Ventilator & $\begin{array}{c}10 \mathrm{~V} / \mathrm{m} \\
(80 \mathrm{MHz}- \\
2.5 \mathrm{GHz})\end{array}$ & Critical \\
\hline 2 & $\begin{array}{l}\text { Carefusion } \\
\text { Infant Flow } \\
\text { Sipap } \\
\end{array}$ & $\begin{array}{l}\text { Respiratory } \\
\text { support }\end{array}$ & $\begin{array}{c}10 \mathrm{~V} / \mathrm{m} \\
(80 \mathrm{MHz}- \\
2.5 \mathrm{GHz}) \\
\end{array}$ & Critical \\
\hline 3 & $\begin{array}{l}\text { Wilamed } \\
\text { Aircon } \\
\text { Humidifier } \\
\text { Heated } \\
\end{array}$ & $\begin{array}{l}\text { Heated air } \\
\text { humidifier }\end{array}$ & $\begin{array}{c}3 \mathrm{~V} / \mathrm{m} \\
(80 \mathrm{MHz}- \\
2.5 \mathrm{GHz})\end{array}$ & Serious \\
\hline 4 & $\begin{array}{c}\text { Fisher \& } \\
\text { Paykel MP } 850\end{array}$ & $\begin{array}{l}\text { Heated air } \\
\text { humidifier }\end{array}$ & $\begin{array}{c}3 \mathrm{~V} / \mathrm{m} \\
(80 \mathrm{MHz}- \\
2.5 \mathrm{GHz}) \\
\end{array}$ & Serious \\
\hline 5 & $\begin{array}{c}\text { B.Braun } \\
\text { Perfusor Space }\end{array}$ & Infusion pump & $\begin{array}{c}10 \mathrm{~V} / \mathrm{m} \\
(80 \mathrm{MHz}- \\
2.5 \mathrm{GHz}) \\
\end{array}$ & Critical \\
\hline 6 & $\begin{array}{c}\text { Philips } \\
\text { Intellivue MX } \\
500 \\
\end{array}$ & \multirow[t]{3}{*}{$\begin{array}{l}\text { Patient } \\
\text { Monitor }\end{array}$} & \multirow{3}{*}{$\begin{array}{c}3 \mathrm{~V} / \mathrm{m} \\
(80 \mathrm{MHz}- \\
2.5 \mathrm{GHz}) 6 \\
\text { Philips } \\
\text { Intellivue X2 } \\
(1 \mathrm{~V} / \mathrm{m} \text { for } \\
\text { respiration and } \\
\text { BIS })\end{array}$} & \multirow[t]{3}{*}{ Serious } \\
\hline 7 & $\begin{array}{c}\text { Philips } \\
\text { Intellivue MX } \\
450 \\
\end{array}$ & & & \\
\hline 8 & $\begin{array}{c}\text { Philips } \\
\text { Intellivue X2 }\end{array}$ & & & \\
\hline 9 & $\begin{array}{c}\text { GE giraffe } \\
\text { Warmer } \\
\text { incubator, } \\
\text { infant, } \\
\text { open/stationary }\end{array}$ & \multirow[t]{2}{*}{$\begin{array}{c}\text { Neonatal } \\
\text { incubator/ } \\
\text { Infant radiant } \\
\text { warmer }\end{array}$} & $\begin{array}{c}10 \mathrm{~V} / \mathrm{m} \\
(80 \mathrm{MHz}- \\
2.5 \mathrm{GHz})\end{array}$ & Serious \\
\hline 10 & $\begin{array}{c}\text { GE giraffe } \\
\text { Warmer } \\
\text { omnibed, } \\
\text { infant, } \\
\text { stationary }\end{array}$ & & $\begin{array}{c}10 \mathrm{~V} / \mathrm{m} \\
(80 \mathrm{MHz}- \\
2.5 \mathrm{GHz})\end{array}$ & Serious \\
\hline
\end{tabular}

Step 3: List all sources of EM radiation:

The possible sources that may affect the ME from Step 2 are listed in Table I. The extra parameter, probability, is introduced here for the application of the risk-based approach. It incorporates the chance of this kind of signal to be present in the environment as well as the capabilities of the signal itself to cause EMI, based on the previously reported cases. The probability can be probable, moderate, or minor. The C2000 is not considered here, as it is used only in the ambulance or by the firefighters to respond to a fire alarm and it happens rarely.

\section{Step 4: Assess the risk of every source-victim pair:}

The sources listed in Table I and the victims listed in Table III are set together creating a source-victim matrix [11] that shows interactions between all of the pairs. It is then possible to group the pairs according to their corresponding severity and probability parameters as shown in Table IV. Depending on the combination of these parameters, it is possible to estimate the overall risk of EMI in the case of the selected pairs. The dark grey, light grey and white color box indicate high risk, medium risk, and low risk, respectively. The source and victims are coded for instance S2V6 means the risk of source 2 interfering on victim 6 . The high-risk cases are for instance the sources with high probability $1,2,3,14$ severely interfering with the victims $1,2,5$. Only the interaction between individual sources and victims is analyzed here. The effect of combined multiple sources on a single victim is a subject of further studies as it can greatly increase the risk of EMI. It can however be investigated using a very similar method.

TABLE IV. RISKS OF SOURCE-VICTIM PAIRS ASSESSED AT THE NEONATOLOGY

\begin{tabular}{|c|c|c|c|c|}
\hline & \multicolumn{3}{|c|}{ Victims(V) } \\
\hline & & Critical & Serious & Negligible \\
\hline \multirow{3}{*}{ 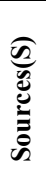 } & Probable & $\begin{array}{c}\mathrm{S}(1,2,3,14) \\
\mathrm{V}(1,2,5)\end{array}$ & $\begin{array}{c}\mathrm{S}(1,2,3,14) \\
\mathrm{V}(3,4,6-10)\end{array}$ & \\
\hline & Moderate & $\begin{array}{c}S(4-9) \\
V(1,2,5)\end{array}$ & $\begin{array}{c}\mathrm{S}(4-9) \\
\mathrm{V}(3,4,6-10)\end{array}$ & \\
\hline & Minor & $\begin{array}{l}S(10-16) \\
V(1,2,5)\end{array}$ & $\begin{array}{c}\mathrm{S}(10-16) \\
\mathrm{V}(3,4,6-10)\end{array}$ & \\
\hline
\end{tabular}

Step 5: Further investigate the high-risk source-victim pairs: Based on the source-victim pair analysis results presented in Table IV, the high-risk cases are selected for further experimental verification. The experimental setup is shown in Fig. 3. It is placed in the actual analyzed EM environment, or possibly a laboratory that best represents the same conditions in terms of reflections. The source consists of a signal generator connected to antenna and is calibrated to mimic the real source in terms of frequency and ERP according to Table I. The victim $\mathrm{ME}$ is placed away from the simulated source and moved towards it until EMI occurs. The detailed flowchart of the test procedure is shown in Fig. 4.

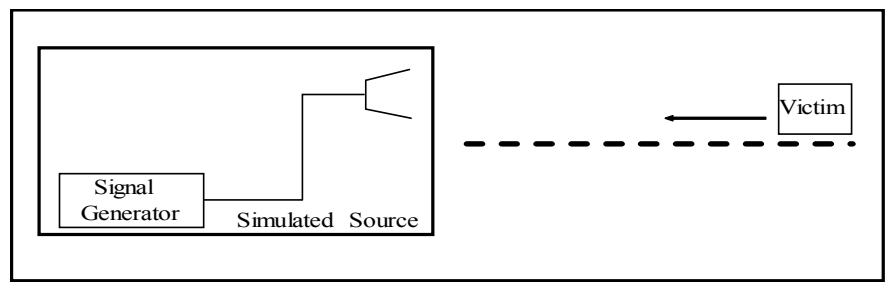

Fig. 3. The experimental setup 


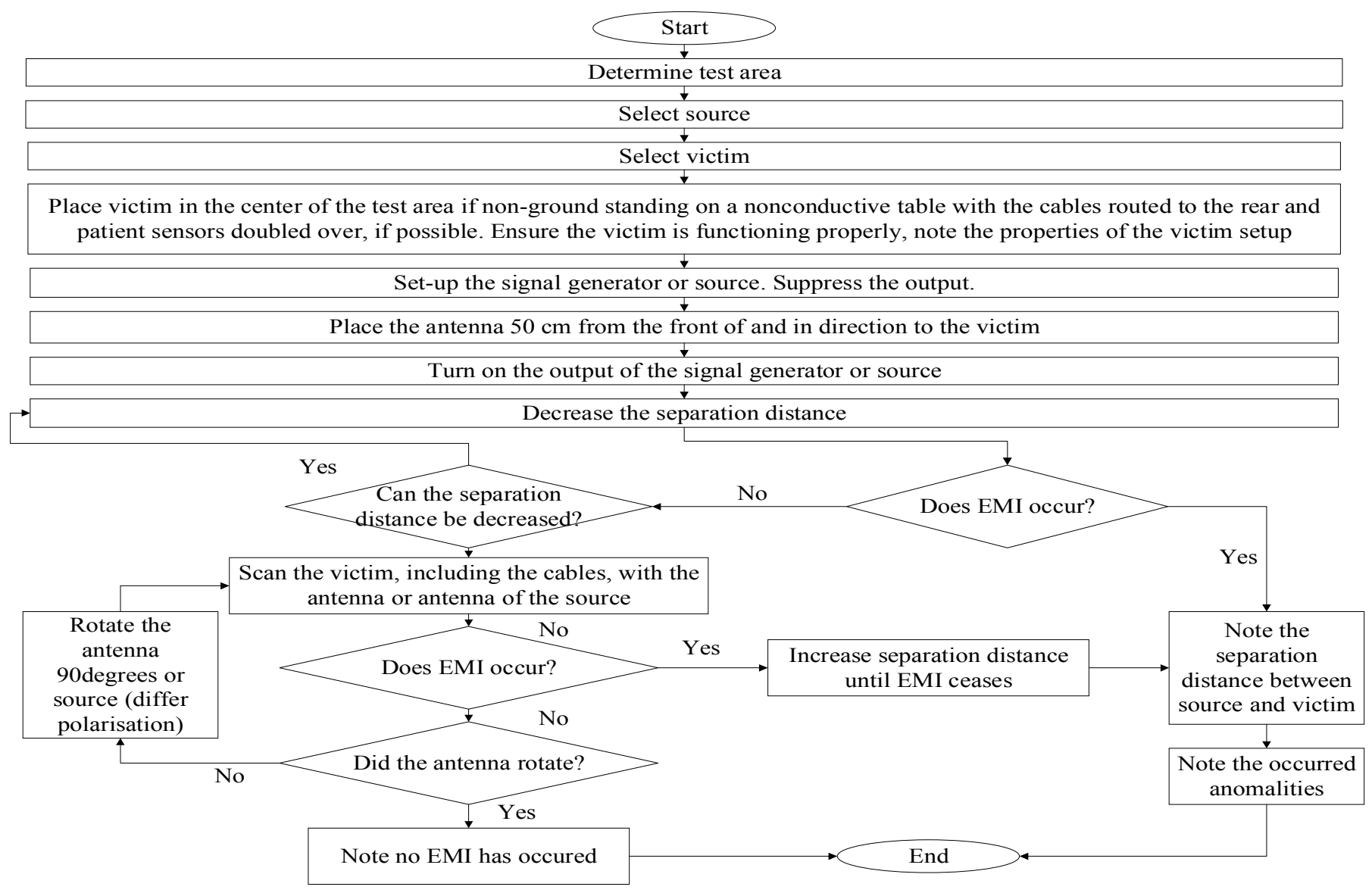

Fig.4. Flowchart of the test procedure

The pulse modulation with a duty cycle of $50 \%$ and a modulation frequency of $200 \mathrm{~Hz}$ is chosen here as a representation of wireless communication sources. Table $\mathrm{V}$ shows the overview result of this test procedure performed in the nanotechnology room, where walkie-talkie (W-T), cell phone $(\mathrm{CP})$, computer and tablet $(\mathrm{C}, \mathrm{T})$ and UPASS and TRANSIT (RFID), all are tested with the corresponding ME. Here " $n$ " means not tested, and "-" means that no EMI was registered in the test.

TABLE V. EMI Distance OF Victims on the NeONATOLOgY

\begin{tabular}{|c|c|c|c|c|c|}
\hline \multirow{2}{*}{ No } & Medical Device & \multicolumn{4}{|c|}{ EMI distance (cm) } \\
\cline { 3 - 6 } & & $\boldsymbol{W - T}$ & $\boldsymbol{C P}$ & $\boldsymbol{C , T}$ & $\boldsymbol{R} F \boldsymbol{I D}$ \\
\hline 1 & Acutronic Fabian & 23 & - & - & - \\
\hline 2 & Carefusion Infant Flow Sipap & 35 & 110 & - & 44 \\
\hline 3 & $\begin{array}{c}\text { Wilamed Aircon Humidifier } \\
\text { Heated }\end{array}$ & 10 & - & $\mathrm{n}$ & - \\
\hline 4 & Fisher \& Paykel MP 850 & 8 & - & $\mathrm{n}$ & - \\
\hline 5 & B.Braun Perfusor Space & - & - & - & - \\
\hline 6 & Philips Intellivue MX 500 & - & - & $\mathrm{n}$ & 300 \\
\hline 7 & Philips Intellivue X450 & - & - & $\mathrm{n}$ & 300 \\
\hline 8 & Philips Intellivue X2 & - & - & $\mathrm{n}$ & 300 \\
\hline 9 & $\begin{array}{c}\text { GE giraffe Warmer incubator, } \\
\text { infant, open/stationary }\end{array}$ & 60 & - & $\mathrm{n}$ & - \\
\hline 10 & $\begin{array}{c}\text { GE giraffe Warmer omnibed } \\
\text { infant, stationary }\end{array}$ & - & - & $\mathrm{n}$ & - \\
\hline
\end{tabular}

Step 6: Apply risk management:

From Table $\mathrm{V}$, it is possible to assess the distance, at which EMI occurs. For example, W-T can interfere with Acutronic Fabian at a distance of $23 \mathrm{~cm}$, but $\mathrm{CP}$ causes EMI even at $110 \mathrm{~cm}$. The values presented here are significantly more reliable than the ones calculated using equation (1), and should define the minimum separation distance to minimize the risk of EMI. Therefore, they create a base for a risk-based EMC management plan regarding those ME. It has to be decided whether respecting the separation distance is sufficient, or other measures such as extra behavioral precautions or even banning the suspected source from the given environment should be taken into account. For example, in the discussed here case at MST, a distance of $100 \mathrm{~cm}$ is advised for $\mathrm{W}-\mathrm{T}$ to minimize the risk of EMI. In addition, the nursing staff has been informed about how to recognize the unexpected behavior of ME due to EMI. The installation of the Nedap RFID transceiver in a fixed position with a separation distance is recommended for UPASS or any other EPC gen II reader e.g. on the patient monitor of the Neonatology could be interfered, although it may or may not be life-threatening. All the above suggestions do not guarantee lack of EMI whatsoever but can significantly help to understand and mitigate issues related to introducing wireless services or devices in a hospital environment. 


\section{CONCLUSION}

It has been shown in this paper that the risk-based EMC approach is more suitable because the rule-based EMC approach presumes perfect free space conditions. In reality, indoor environments are not laboratories, where the equipment was tested according to the standard IEC 61000-4-3 Ed.32006. Various sources can generate electric fields of different intensities when placed in real environments. So we can use the source victim-matrix to generate a table of risks addressing the humans. According to the steps presented in this paper, performing actual verification helps to make these cases more reliable. Therefore, we can conclude that the risk-based EMC approach is necessary to fully control the environment as well as all the wireless electronic devices within that which can contribute to the EMI.

The effects of multiple sources interfering with a single victim, as well as a deeper analysis of the signal properties of various systems including their time and frequency behavior, and impact of indoor propagation including multiple reflections, will be incorporated in the presented risk-based approach. As new sources of EM radiation, like 5G, will appear in the hospital, the research will also include these potential risks.

\section{REFERENCES}

[1] A. R. Kall, "Compatibility of Medical Electronic Instrumentation with the EMI Environment in Hospitals," 1973 1EEE International Electromagnetic Compatibility Symposium Record, New York, NY, 1973, pp. 1-1.

[2] J. L. Silberberg, "An FDA Perspective on Medical Device EMC and Wireless WED-PM-4," 2018 IEEE Symp. Electromagn. Compat. Signal Integr. Power Integrity, EMC, SI PI 2018, 2018, d

[3] H. Magsi, A. H. Sodhro, F. A. Chachar, S. A. K. Abro, G. H. Sodhro and S. Pirbhulal, "Evolution of 5G in Internet of medical things," 2018 International Conference on Computing, Mathematics and Engineering Technologies (iCoMET), Sukkur, 2018, pp. 1-7
[4] K. Kuperus and B. van der Schrier, "The MedTech market in the Netherlands," pp. 1-56, 2017.

[5] MedTech Europe, "The European Medical Technology Industry," Eucomed Organ., p. 12, 2013.

[6] E. Ing, K. Armstrong, and S. Mieee, "Another EMC resource from EMC Standards EMC requirements in IEC60601-1-2 Taster The medical EMC requirements in IEC 60601-1-2's 2007 and 2014 editions," vol. 44, no. 0, pp. $0-4$.

[7] "March 2018 Guide for the EMCD ( Directive 2014 / 30 / EU )," no. March, pp. 1-67, 2018.

[8] Mumpy Das, "Risk-based EMC Approach in Hospital Environment" in press SIPI- EMC Reno 2020 conference.

[9] F. Leferink, "Risk-based vs Rule-based Electromagnetic Compatibility in Large Installations," 2018 IEEE 4th Glob. Electromagn. Compat. Conf. GEMCCon 2018, pp. 1-4, 2019,

[10] F. Leferink, J. van der Ven, H. Bergsma and B. van Leersum, "Risk based EMC for complex systems," 2017 XXXIInd General Assembly and Scientific Symposium of the International Union of Radio Science (URSI GASS), Montreal, QC, 2017.

[11] R. Harris, "A Practical Approach to Risk Assessment and Risk Reduction Today 's Learning Objectives," 2012 [online] Available http://www.cmafh.com/enewsletter/PDFs/Machine Safety_Risk\%2 0Assessment_SafetyII.pdf

[12] V. Dafinescu, V. David, and I. Nica, "Medical devices electromagnetic interference due to radiated emissions in the hospital," 2011 E-Health Bioeng. Conf. EHB 2011, pp. 1-4.

[13] B. View, "855 indexed reports of EMI," vol. 44, no. March, 2015.

[14] A. Fehske, G. Fettweis, J. Malmodin, and G. Biczok, "The global footprint of mobile communications: The ecological and economic perspective," IEEE Commun. Mag., vol. 49, no. 8, pp. 55-62, 2011,. Matthew Pinchuk Meland and Anthony Dedes, "Electrocardiogram (ECG) Susceptibility to Interference from Popular Electronic Devices", IEEE EMC Society Newsletter, Winter 2007

[16] CADTH, "Wireless Device Use and Patient Monitoring Equipment in Any Healthcare Delivery Setting: A Review of Safety and Guidelines," no. January, 2014,

[17] BBC News report "Hospital risk from radio tags" at http://news.bbc.co.uk/go/pr/fr/-/1/hi/health/7471008.stm..

[18] International Electrotechnical Commission, "International Standard Basic EMC Publication," no. 183493, p. 84, 2002.

[19] F. B. J. Leferink, D. J. G. Boerle, and F. A. G. Sogtoen, "In-situ EMI Measurements Using a Vibrating Intrinsic Reverberation Chamber," Internatioanl Sympoisium EMC Eur., 2000. 